\title{
Pull-out behaviour of steel fibres in cracked concrete under wet-dry cycles - deterioration phenomena
}

Marcos-Meson, V.; Solgaard, A.; Skovhus, T.L.; Jakobsen , U.H.; Fischer, G.; Edvardsen, C.; Michel, A.

Published in:

Magazine of Concrete Research

Link to article, DOI:

10.1680/jmacr.19.00448

Publication date:

2021

Document Version

Peer reviewed version

Link back to DTU Orbit

Citation (APA):

Marcos-Meson, V., Solgaard, A., Skovhus, T. L., Jakobsen, U. H., Fischer, G., Edvardsen, C., \& Michel, A.

(2021). Pull-out behaviour of steel fibres in cracked concrete under wet-dry cycles - deterioration phenomena. Magazine of Concrete Research, 73(16), 843-852. https://doi.org/10.1680/jmacr.19.00448

\section{General rights}

Copyright and moral rights for the publications made accessible in the public portal are retained by the authors and/or other copyright owners and it is a condition of accessing publications that users recognise and abide by the legal requirements associated with these rights.

- Users may download and print one copy of any publication from the public portal for the purpose of private study or research.

- You may not further distribute the material or use it for any profit-making activity or commercial gain

- You may freely distribute the URL identifying the publication in the public portal 


\title{
Pull-out behaviour of steel fibres in cracked concrete exposed to wet-dry cycles - deterioration phenomena
}

\author{
V. Marcos-Meson ${ }^{1,2,3^{*}}$, A. Solgaard ${ }^{2}$, T.L. Skovhus ${ }^{3}$, U.H. Jakobsen ${ }^{4}$, G. Fischer ${ }^{1}$, C. Edvardsen² and A. \\ Michel $^{1}$ \\ ${ }^{1}$ Department of Civil Engineering, Technical University of Denmark, Copenhagen, Denmark \\ ${ }^{2}$ COWI A/S, Copenhagen, Denmark \\ ${ }^{3}$ VIA Building, Energy, Water \& Climate, VIA University College, Horsens, Denmark \\ ${ }^{4}$ Danish Technological Institute, Taastrup, Denmark \\ * Corresponding author: vicmes@byg.dtu.dk
}

\begin{abstract}
This paper presents observations and results of an experimental investigation on the mechanisms altering the pull-out behaviour of partially pulled hooked-end steel fibres inside an artificial crack exposed to wet-dry cycles for six months. Mechanical and corrosion damage at the surface of the steel fibre were investigated by 3D optical interferometric profiling and petrographic analyses to describe mechanical damage and healing processes at the matrix surrounding the fibre. Mechanical damage observed in the cementitious matrix and at the fibre confirmed that, after debonding, the pull-out process was governed by yielding of the fibre hook, fracture of the adjacent matrix and friction between the hook and the matrix. The partial restoration of the adhesive bond after exposure was attributed to a combination of autogenous healing around the fractured fibrematrix interface and accumulation of corrosion products around the intersection of the fibre with the crack. The increase of the mechanical bond strength was ascribed to autogenous healing processes at the mechanically damaged matrix around the fibre hook. Results of this study support the hypothesis that the increase of the pull-out force transferred by hooked-end steel fibres bridging cracks in concrete exposed to wet-dry cycles is mainly related to autogenous healing and carbonation of the damaged matrix around the fibre than corrosion damage of the steel.
\end{abstract}

\section{Keywords}

Steel Fibre Reinforced Concrete (SFRC); cracks; chlorides; carbonation; corrosion; petrography; autogenous healing; pull-out

\section{Introduction}

There is disagreement regarding the role of fibre corrosion in the long-term mechanical performance of cracked Steel Fibre Reinforced Concrete (SFRC) under exposures involving wet-dry conditions [1]. Studies investigating the mechanical performance of SFRC reinforced with hooked-end fibres have reported considerable alteration of the residual tensile strength of the cracked SFRC, which was generally attributed to an increase of the fibre-matrix bond strength due to corrosion [2] or to additional hydration of the cement matrix $[3,4]$. Yet, recent investigations suggest that increases of the residual tensile strength of cracked SFRC may be related instead to autogenous healing of damage in the cement matrix around partially-pulled fibres $[5,6]$.

Investigation of the cause for such variations of the residual tensile strength of the cracked SFRC require a detailed understanding of the pull-out behaviour of hooked-end fibres in concrete, i.e. the fibre matrix bond. The bond of an aligned hooked-end fibre embedded in a cementitious matrix is ascribed to three bond mechanisms, that partly overlap during the 
pull-out process of hooked-end fibres: the adhesive bond, and the mechanical and frictional bond $[7,8]$. After the utilization of the adhesive bond, at displacement values of approx. $20-30 \mu \mathrm{m}$ [9], the pull-out behaviour of the fibre is primarily governed by the mechanical and frictional anchorage transferred trough the hook. These result in substantial mechanical damage to the cement matrix surrounding the hook [10-13], which facilitates the pull-out process of the fibre.

Studies investigating the pull-out behaviour of aligned fibres bridging an artificial crack in a cementitious matrix exposed to wet-dry cycles of saltwater have reported increases in the maximum pull-out force after the exposure [14,15]. A recent investigation on partially-pulled fibres exposed to wet-dry cycles of saltwater and freshwater described a partial recovery of the adhesive bond between the fibre and the matrix, and a significant increase of the mechanical bond strength [9].

Former studies ascribed the increase of the fibrematrix bond strength after exposure to an increase of the frictional resistance due to fibre corrosion, i.e. due to localized expansion of corrosion products at the hook [15] or an increase of the fibre roughness over the whole fibre surface [14]. The latter hypothesis was also suggested in a study investigating precorroded fibres embedded in mortar [16]. However, these hypotheses are not fully consistent with the increases of the fibre-matrix bond strength shown in experiments that did not involve corrosion damage, such as for de-bonded steel and polymer fibres cured in freshwater [17-19]. Other studies propose instead that the increase of the fibre-matrix bond strength is governed by an alteration of the microstructure of the damaged matrix around the fibre, referred to as autogenous healing processes $[9,17]$.

This investigation aims at describing the deterioration processes that govern the changes in the pull-out behaviour of partially pulled steel fibres from concrete exposed to wet-dry cycles reported in [9], testing the compatibility and validity of the aforementioned hypotheses. The studies herein describe the alteration of the surface of the steel fibre due to mechanical and corrosion damage and the mechanical damage and microstructural changes at the matrix surrounding the fibre.

\section{Methodology}

The investigations covered the preparation, exposure and inspection of single fibre pull-out specimens, partially pulled-out to induce mechanical damage equivalent to crack widths in the range of $0.2-0.3$ $\mathrm{mm}$ and exposed to wet-dry cycles for six months. The exposures investigated comprise wet-dry cycles

of saltwater and freshwater with a high carbon dioxide concentration. Single-fibre specimens were investigated in a single-sided test, based on the setup described in $[9,20]$. The specimens inspected in this study corresponded to companion specimens to the ones investigated in [9]. Inspection of damage in the matrix was undertaken by means of petrographic analysis, whereas measurement of the extent of corrosion damage and accumulation of corrosion products was done by 3D optical interferometric profiling.

Table 1. Mix-design. After [9].

\begin{tabular}{cc}
\hline Component & $\begin{array}{c}\text { Quantity } \\
\left(\mathbf{k g} / \mathbf{m}^{\mathbf{3}}\right)\end{array}$ \\
\hline Cement (CEM I 52.5N) & 326.3 \\
Fly Ash & 100 \\
Water & 145 \\
Sand 00/02 & 787.4 \\
Sea gravel 04/08 & 1036.5 \\
Entrained air & $3 \%$ \\
\hline
\end{tabular}

\subsection{Preparation of specimens}

The pull-out specimens investigated were cast using the mix-design presented in [9]. The total binder content was $426.3 \mathrm{~kg} / \mathrm{m}^{3}$ with 31 -wt.\% fly ash replacement of the Portland cement, and the water to binder ratio was 0.34 , see Table 1 . The superplasticizer content was adjusted in the subsequent mixes to reach a flow diameter of $120 \pm 20$ mm, measured according to EN 1015-3:1999 [21] and the air-entrainer content was adjusted to reach a level of entrained air of $3.0 \pm 0.5 \mathrm{vol} . \%$, measured according to EN 413-2:2016 [22]. The steel fibre investigated was made of cold-drawn carbon-steel wire with a characteristic tensile strength of $1800 \mathrm{MPa}$, hooked ends (type 1 according to EN 14889-1:2006 [23]), a length of $60 \mathrm{~mm}$ and a diameter of $0.75 \mathrm{~mm}$, see Fig. 1 a.

The specimens were mixed using a $60 \mathrm{~L}$ planetary mixer, cast using PVC formworks over a vibration table. The fibres were held to the bottom plate of the PVC formwork using a perforated rubber plug

a)

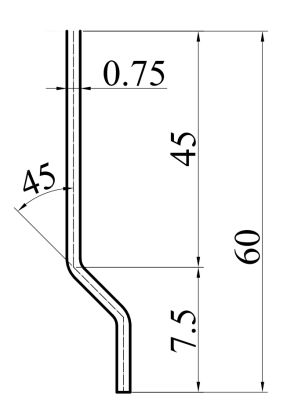

Fig. 1. Dimensions of a) steel fibre and b) pull-out specimen. Dimensions are expressed in mm. After [9]. 
inserted into a conic gap at the centre of the bottom surface of the form, maintaining a $90^{\circ}$ angle with the bottom of the formwork.

The specimens exposed to saltwater and freshwater were partially pulled-out up to a slip value of $0.15 \mathrm{~mm}$ before the exposure. The upper surface of the specimens was covered with a $50 \times 50 \mathrm{~mm}$ acetate film, leaving a separation between the film and the concrete surface of approx. $0.3 \pm 0.1 \mathrm{~mm}$, mimicking exposure of a single fibre in cracked concrete environment. The part of the fibre exposed to the surface out was covered with heavy-duty marinegrade epoxy paint, see Fig. 1b.

\section{$2.2 \quad$ Exposure setup}

The investigated specimens were coded according to the number of sample (from 1 to 4 ) and the type of study including thin-sections $(\mathrm{T})$, polished sections (P) and 3D optical profiles (O). The exposure environments are described in Table 2 and comprised wet-dry cycles exposure of partially pulled specimens exposed to saltwater and freshwater. Reference specimens were also tested after curing immersed in limewater for 56 days.

The specimens cured in limewater were immersed in the solution at all times. The wet-dry exposure setup consisted of two rectangular polyethylene containers of approx. $200 \mathrm{~L}$ each, one used for each exposure. The wet-dry cycles for the freshwater and saltwater exposure were controlled automatically, with a total cycle length of four days, as described in [9].

During the wet cycle (two days), the specimens were covered completely with the solution. The solution was replaced every two weeks during the first two months of exposure and every month up to 6 months, and was checked weekly by means of electrical resistivity and $\mathrm{pH}$ measurements. Non-chlorinated water $\left(\mathrm{pH}=7.5-8.0, \mathrm{Cl}^{-}<100 \mathrm{mg} / 1,16-17^{\circ} \mathrm{dH}\right)$ was used as exposure media for the specimens subjected to freshwater cycles and to prepare the a)

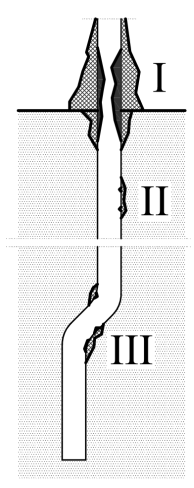

b)

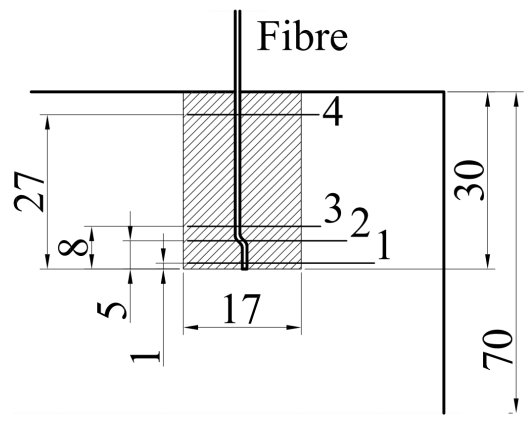

Fig. 2. Location of inspection areas of specimens: a) inspection areas for 3D optical profiles, after [9], and b) location of thin-sections and inspection area of polished sections.

saltwater brine. The solution of specimens cured in limewater was not replaced, and the $\mathrm{pH}$ value in the solution was kept in the range of $10-13$ by addition of approx. $25 \mathrm{cl}$ of saturated solution of calcium hydroxide every two weeks.

The drying cycle for the specimens exposed to laboratory air was provided by two inlet fans with a total nominal flow of $100 \mathrm{~m}^{3} / \mathrm{h}$ and two outlets placed at opposite ends at the top of the tank. The air was kept at stable temperature, humidity and $\mathrm{CO}_{2}$ concentration by the ventilation system of the building and was monitored weekly, being $20 \pm 2{ }^{\circ} \mathrm{C}$, $50 \pm 10 \%$ and $0.05 \pm 0.01$-vol. $\%$ respectively. The drying cycle of the carbon dioxide exposure had a nominal flow of approx. $90 \mathrm{~m}^{3} / \mathrm{h}$, running through a closed loop and utilized a cooled heat exchanger to condensate moisture from the air flux. The $\mathrm{CO}_{2}$ concentration inside the carbon dioxide loop was measured weekly and was approx. $0.5 \pm 0.1-$ vol.\%.

\subsection{Experimental studies}

\subsubsection{Optical inspection of fibres}

The surface of pulled-out steel fibres from selected specimens was inspected using a 3D optical

Table 2. Test samples and exposure conditions. After [9].

\begin{tabular}{|c|c|c|c|c|c|c|}
\hline \multicolumn{2}{|c|}{ Sample } & Study & Presented & $\begin{array}{c}\text { Pull } \\
(\mathrm{mm})\end{array}$ & Wet cycle & Dry cycle \\
\hline \multirow{3}{*}{1} & $\mathrm{~T}$ & Thin-section & $\mathrm{x}$ & \multirow{3}{*}{0.15} & \multirow{3}{*}{7 -wt. $\% \mathrm{NaCl}$} & \multirow{3}{*}{0.05 -vol. $\% \mathrm{CO}_{2}$} \\
\hline & $\mathrm{P}$ & Polished-section & $\mathrm{x}$ & & & \\
\hline & $\mathrm{O}$ & 3D profile & $\mathrm{x}$ & & & \\
\hline \multirow{3}{*}{2} & $\mathrm{~T}$ & Thin-section & $\mathrm{x}$ & \multirow{3}{*}{0.15} & \multirow{3}{*}{ Freshwater } & \multirow{3}{*}{0.5 -vol. $\% \mathrm{CO}_{2}$} \\
\hline & $\mathrm{P}$ & Polished-section & & & & \\
\hline & $\mathrm{O}$ & 3D profile & $\mathrm{x}$ & & & \\
\hline \multirow{3}{*}{3} & $\mathrm{~T}$ & Thin-section & $\mathrm{x}$ & \multirow{3}{*}{0.15} & \multirow{3}{*}{ Limewater } & \multirow{3}{*}{-} \\
\hline & $\mathrm{P}$ & Polished-section & & & & \\
\hline & $\mathrm{O}$ & 3D profile & $\mathrm{x}$ & & & \\
\hline \multirow{2}{*}{4} & $\mathrm{~T}$ & Thin-section & $\mathrm{x}$ & \multirow{2}{*}{0} & \multirow{2}{*}{ Limewater } & \multirow[t]{2}{*}{-} \\
\hline & $\mathrm{O}$ & $3 \mathrm{D}$ profile $*$ & $\mathrm{x}$ & & & \\
\hline
\end{tabular}

Note: Each sample corresponds to a separate specimen, prepared and tested as the others. Except for (5S):

* The fibre scanned was tested as supplied, before being embedded in the matrix. 
interferometry profiler (Keyence VR-3000 G2) with a resolution of $0.1 \mu \mathrm{m}$. The inspection was done on three locations of the fibre, shown in Fig. 2a: I) the steel exposed to the solution inside the artificial crack, II) the central part of the fibre stem, III) the intermediate part of the hook.

The analysis focused on describing the roughness and volume of corrosion products to determine whether an alteration of the steel surface due to corrosion damage may have an impact on the pull-out behaviour of the fibre. The analysis of the corrosion damage and accumulation of corrosion products on the exposed steel surface (Location I in Fig. 2a) was done on a $3 \mathrm{D}$ reconstruction of approx. $1 / 3$ of the fibre's cross-section, due to limitations in the maximum scan area. The analysis of the surface roughness of the steel at the embedded parts of the fibre (Locations II and III in Fig. 2a) was done on a flattened surface profile, reconstructed from a 3D scan, as shown Fig. 3. The analysis of the surface roughness was done on an average surface of $1.5 \mathrm{x}$ $0.5 \mathrm{~mm}$, characterized according to selected parameters described in ISO 25178-2: 2012:

i) The arithmetical mean height $\left(\mathrm{S}_{\mathrm{a}}\right)$ that describes an absolute value of the sum of the height difference of each point to the arithmetical mean of the surface.

ii) The maximum height $\left(\mathrm{S}_{z}\right)$ that represents the sum of the largest peak height value and the largest pit depth.

iii) The root mean square height $\left(\mathrm{S}_{\mathrm{q}}\right)$ that corresponds to the root mean square value of the absolute height values within the area, comparable to the standard deviation of the heights.

iv) The density of peaks $\left(\mathrm{S}_{\mathrm{pd}}\right)$ that describes the average number of peaks per unit area.

\subsubsection{Petrographic study}

The preparation techniques for the petrographic specimens corresponded to those described in $[24,25]$. The stabilization and initial preparation process comprised the following: i) drying of pull-out specimens in laboratory air for 2 weeks, ii) vacuum resin impregnation of the pull-out specimens to stabilize the fibre, iii) sawing of the specimen at the central section surrounding the embedded fibre (i.e. $10 \times 10 \times 40 \mathrm{~mm}$ prism) and drying in oven at $35^{\circ} \mathrm{C}$ for approx. 10 hours. After this process, two types of specimens were prepared, i.e. polished sections longitudinal to the fibre axis and thin-sections transversal to the fibre axis, respectively.

Polished sections were prepared on a plane parallel to the longitudinal axis of the fibre, from the intersection of the fibre with the artificial crack to the hooked-end, a)

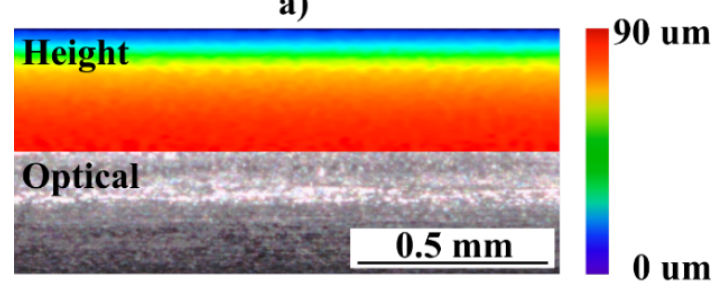

b)

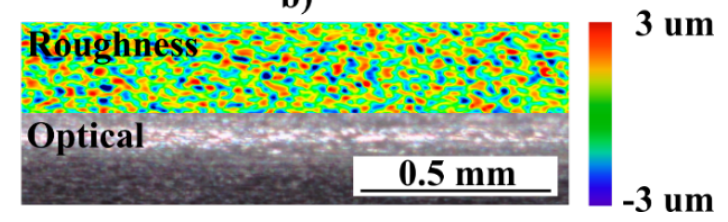

Fig. 3. 3D scans of fibre surface embedded in concrete, at the fibre stem, showing: a) original 3D scan with height profile,

b) flattened surface with roughness profile.

shown as a shaded area in Fig. 2 b. The preparation process comprised: i) sawing of the specimen longitudinal to the fibre, at approx. $1 \mathrm{~mm}$ to the surface of the fibre, ii) vacuum resin impregnation, iii) grinding of the specimen surface until reaching the steel fibre, iv) vacuum resin impregnation, v) lapping and polishing until reaching the central axis of the fibre.

Thin-sections were prepared on four consecutive slices, perpendicular to the direction of the fibre, at the locations shown in Fig. 2b. The preparation process consisted on: i) sawing off four slices perpendicular to the direction of the fibre, ii) vacuum resin impregnation, iii) mounting of four slices into one section, iii) subsequent grinding, lapping and polishing to prepare the thin-section.

The polished sections were photographed under UV light at 50 MP resolution using a $65 \mathrm{~mm} \mathrm{f} / 2.81-5 \mathrm{x}$ macro lens. The thin-sections were analysed by optical polarizing microscopy, using a Leica DM2500P optical polarizing microscope equipped with a UV fluorescent light source. The fluorescent filter combination used was a BG12 excitation filter and a K530 yellow blocking filter, as utilized in [26].

\section{Experimental results}

\subsection{Inspection of fibre surface}

Selected steel fibres were inspected after pull-out and before being embedded in the matrix. The results presented comprise two groups of measurements: i) characterization of the variation of the cross-section of the fibre at the area where the fibre intersects with the crack due to corrosion, and ii) characterization of surface roughness of the steel embedded in the matrix.

Accumulation of corrosion products was observed around the intersection between the fibre and the artificial crack, extending approximately $1-2 \mathrm{~mm}$ 
a)

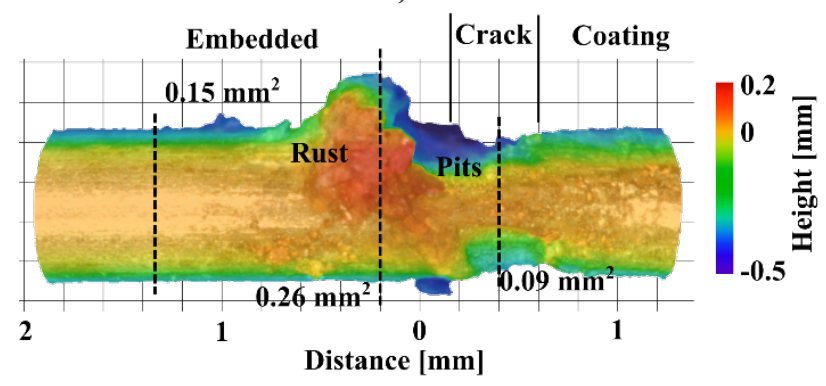

b)

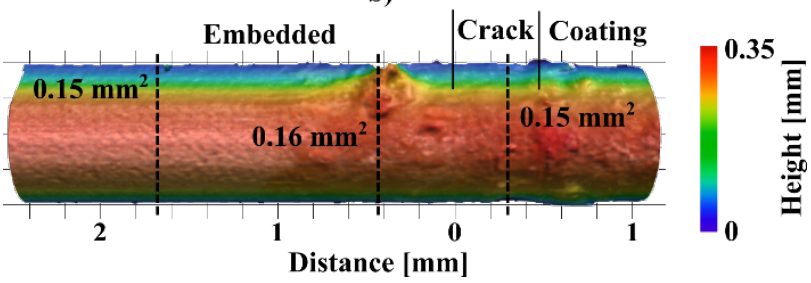

Fig. 4. 3D scan of fibre exposed to saltwater at the intersection with the crack for: a) specimen exposed to saltwater wet-dry cycles, and b) specimen exposed to freshwater wet-dry cycles. The colour map shows the relative height of the surface. The scanned cross-section at three locations was calculated in $\mathrm{mm}^{2}$ (the cross-section inspected was approx. $1 / 3$ of the total cross-section of the fibre).

inside the matrix. Formation of corrosion products (i.e. rust) in this area for the specimen exposed to saltwater, led to an effective increase of the fibre cross-section (i.e. up to $\approx 70 \%$ increase in crosssection), see Fig. 4a. Alongside, there was a substantial reduction of the fibre's cross-section exposed inside the crack (i.e. up to $\approx 40 \%$ reduction of cross-section), which spread slightly into the matrix and the epoxy coating. This was not the case for specimens exposed to freshwater, see Fig. $\mathbf{4 b}$, which showed a minor variation in the fibre crosssection due to corrosion.

Inspection of the surface roughness of the embedded fibre parts was done on a flattened profile, levelled to the mean profile of the 3D scan (as shown in Fig. 3). The analysis was done on two representative locations of the steel fibre: at the fibre stem (see Fig. 5a-b) and at the straightened part of the hook after pull-out (see Fig. 5c). Surface roughness parameters calculated according to (ISO 25178-2: 2012) are presented in Table 3.

Table 3. Roughness parameters from flattened of 3D scans at the embedded parts of the fibre, calculated according to ISO 25178.

\begin{tabular}{|c|c|c|c|c|c|}
\hline \multicolumn{2}{|c|}{ Specimen } & $\begin{array}{c}S_{a} \\
\mu m\end{array}$ & $\begin{array}{c}S_{z} \\
\mu m\end{array}$ & $\begin{array}{c}\mathrm{S}_{\mathrm{q}} \\
\mu m\end{array}$ & $\begin{array}{c}S_{\mathrm{pd}} \\
1 / \mathrm{mm}^{2}\end{array}$ \\
\hline $1 \mathrm{~S}$ & I & 0.98 & 11.7 & 1.25 & 1245 \\
\hline $1 \mathrm{~S}$ & II & 1.07 & 23.9 & 1.49 & 1269 \\
\hline $2 \mathrm{~S}$ & I & 1.03 & 13.0 & 1.30 & 1387 \\
\hline $2 \mathrm{~S}$ & II & 1.26 & 18.1 & 1.62 & 1294 \\
\hline $3 \mathrm{~S}$ & I & 0.93 & 12.1 & 1.19 & 1442 \\
\hline $4 \mathrm{~S}$ & I & 1.06 & 16.2 & 1.37 & 1449 \\
\hline
\end{tabular}

Abbreviations: $\left(S_{a}\right)$ arithmetical mean height, $\left(S_{z}\right)$ maximum height, $\left(S_{q}\right)$ root mean square height, and $\left(S_{p d}\right)$ density of peaks. a)

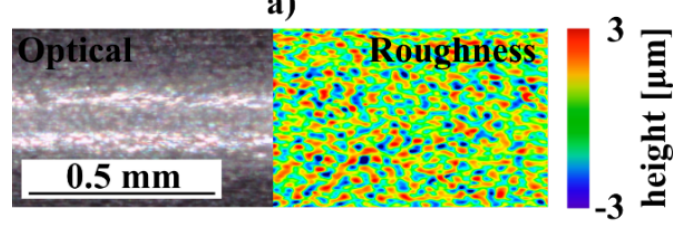

b)

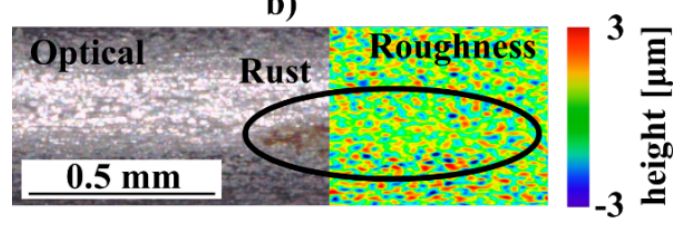

c)

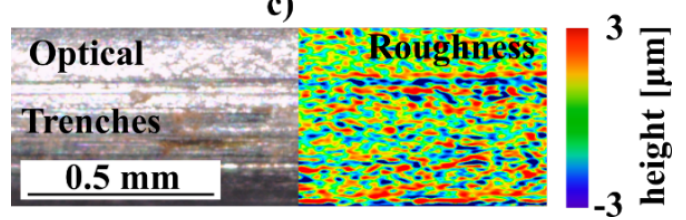

Fig. 5. 3D scans of fibre surface embedded in concrete: a) surface roughness at the stem of an exposed fibre (2S-I); b)

surface roughness around a rust spot at the stem of an unexposed fibre (4S-I), c) surface roughness at the

straightened section of the hook of a pulled-out fibre (2S-II).

The steel surface showed a generally uniform distribution of peaks and pits at the steel surface, see Fig. 5a. Localized areas presenting rust stains were found in exposed and unexposed specimens, in the latter these were attributed to oxygen corrosion during storage, handling and preparation of the specimens. Yet, the presence of rust spots did not alter substantially the average roughness measured of the inspected surface, slight decrease of roughness was observed instead (see Fig. 5b). Conversely, there was a clear difference in roughness of the fibres after pullout in the hook region, as shown in Fig. 5c. The steel presented deep longitudinal "trenches" at the straightened hook, which can be attributed to the friction between the steel surface and the surrounding matrix during the pull-out process. Thus, indicating that this area transferred most of the friction during pull-out. The roughness parameters presented in Table 3 confirm that, at the fibre stem, fibres are similar to each other, regardless of the exposure conditions; while major increase in roughness was measured at the hook region of pulled-out fibres, regardless of the exposure conditions as well.

\subsection{Petrographic study}

A petrographic study was carried out to assess the extent of mechanical damage and microstructural alteration of the matrix surrounding the partiallypulled steel fibres before and after exposure. Focus was set on connecting macro- and micro-structural damage in the matrix surrounding the fibre and the pull-out mechanisms of the fibre. Selected results from one specimen exposed to freshwater cycles (specimen 2P in Table 2) are presented below. The extent and nature of the mechanical damage along a 
a)

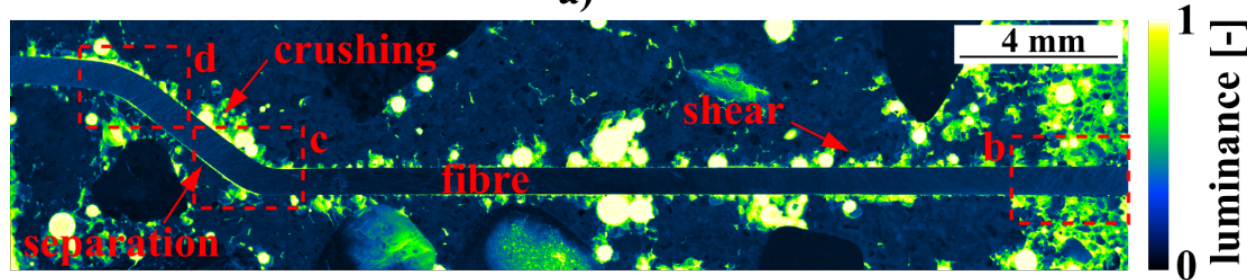

b)

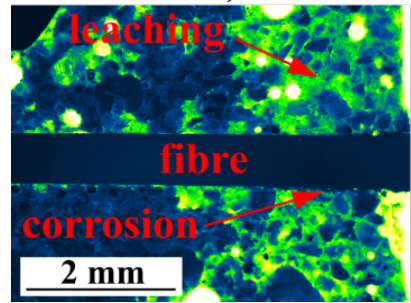

c)

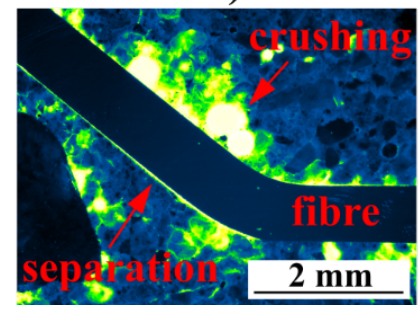

partially-pulled fibre is shown in Fig. 6 as the relative luminance values of a micrograph under UV fluorescent light. The results show areas with voids, higher porosity or mechanical damage in light green/yellow colour and denser areas in darker blue colour.

The results presented in Fig. 6a show that there is an increase in porosity at the outermost $2-3 \mathrm{~mm}$ of the specimen, inside the artificial crack, which are attributed to leaching and carbonation of the matrix during the exposure. In this case, there is accumulation of corrosion products at the outermost $2 \mathrm{~mm}$ of the fibre, which block separation damage and pores in the matrix around this part of the fibre, see Fig. 6b. There is substantial porosity and damage along the stem of the fibre, yet the damage does not seem to form a continuous path along the fibre stem, see Fig. 6a. Most of the mechanically-induced damage to the matrix concentrates around the fibre hook, see Fig. 6a. The side of the hook that faces the pull-out direction generally presents crushing damage, while the opposite side is separated a few micrometres from the matrix, as shown in Fig. 6 c,d. This damage is localized around the hook bends, see Fig. 6c,d. There was no indication of additional transformation of the matrix around the fibre due to exposure at this scale, e.g. autogenous healing or carbonation of the cement paste.

Results from the inspection of thin-sections are presented for selected cross-sections of the fibre in one specimen exposed to wet-dry cycles of saltwater (see Fig. 7), and selected features of various exposed and unexposed specimens (see Fig. 8). The micrographs presented comprise overlays of the inspected areas under cross-polarized and UVfluorescent light, denoted in the figures as "x-pol" and "fluo", respectively.

The inspection of the specimen exposed to wet-dry cycles of saltwater was done at the locations described in Fig. 2: I) at approximately $2 \mathrm{~mm}$ from (Fig. 7d). a)

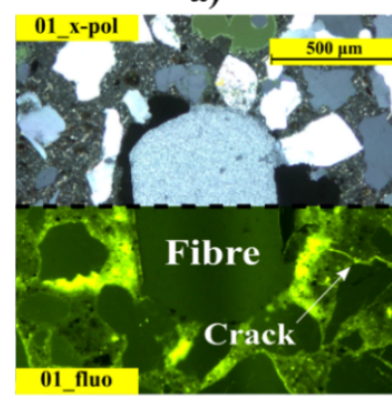

c)

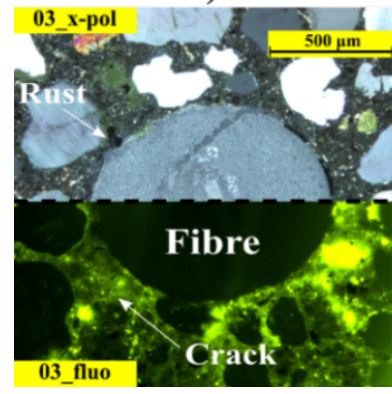

Fig. 6. Polished section of partially pulled-out steel fibre, exposed to freshwater wet-dry cycles (specimen 2P), showing relative UV luminance values for: a) overview of the fibre with indication of local damage; b) intersection of the fibre with the artificial crack; c) first bend of the hook; d) second bend of the hook. The annotations in red indicate damage and features observed in the section under visible and UV light up to $x 5$ magnification.

the intersection of the fibre with the artificial crack (Fig. 7a), II) at the end of the stem, close to the first bend of the hook (Fig. 7b), III) at the second bend of the hook (Fig. 7c), IV) at the straight end of the hook

The micrographs taken under UV fluorescent light show substantial mechanical damage at the matrix adjacent to the fibre, particularly at the hook bends (Fig. 7b,c) and at the intersection of the fibre with the crack (Fig. 7a). This damage generally comprises well-defined radial cracks smaller than $10 \mu \mathrm{m}$ (Fig. 7a), and overall increase in porosity (Fig. $\mathbf{7 b}, \mathbf{c})$. The latter may be related to crushing of the matrix around the fibre, which appears smeared in the thin-section and cannot be fully investigated at the scales observed

b)

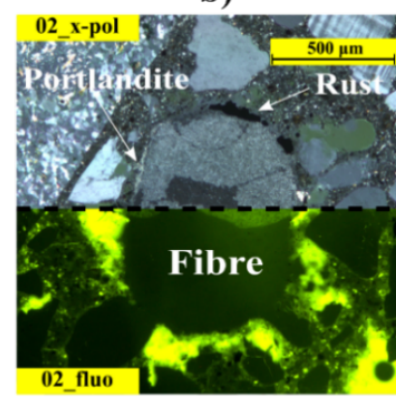

d)

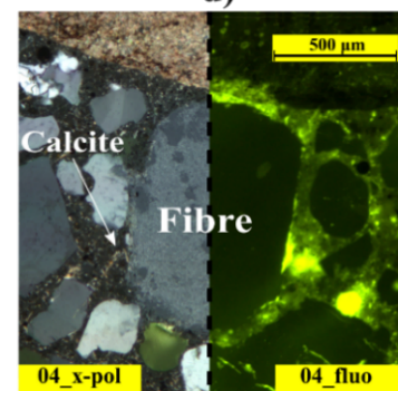

Fig. 7. Thin-section of partially pulled-out fibre exposed to saltwater (specimen 1T), under cross-polarized and UV fluorescent light, at selected locations: a) at the intersection of the fibre with the simulated crack (location I); b) at the stem of the fibre (location II); c) at the centre of the fibre hook (location III); and d) at the end of the fibre hook (location IV). Locations correspond to the ones described in Fig. 2. 
a)

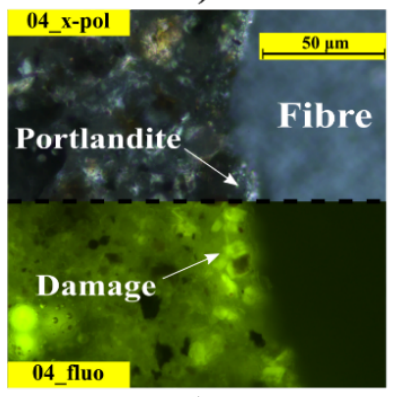

c)

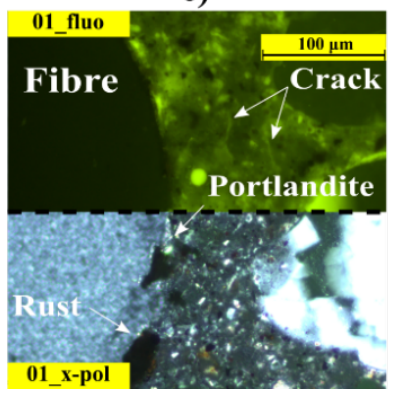

b)

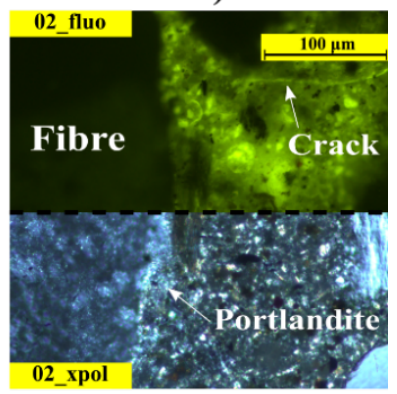

d)

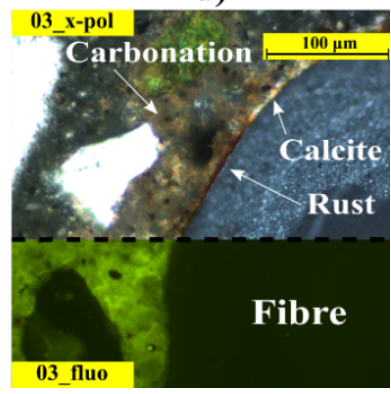

Fig. 8. Thin-section of steel partially pulled-out fibre under cross-polarized and UV fluorescent light, for selected exposures: a) unexposed specimen (specimen $3 \mathrm{~T}$ at location II); b) specimen exposed to freshwater (specimen $2 \mathrm{~T}$ at location III); c) specimen exposed to saltwater (specimen 1T at location II); and d) specimen exposed to saltwater (specimen $1 \mathrm{~T}$ at location III).

with this method. Part of the additional porosity observed at the outermost section (Fig. 7a), may be as well linked to leaching processes in the matrix adjacent to the crack, as shown in Fig. 6a.

Corrosion products were found at the intersection of the fibre with the crack (Fig. 7a), filling porosity and damage around the fibre. There is also smaller accumulation of rust at some locations in the hook region, filling as well separation between the matrix around the steel, see Fig. $\mathbf{7 b , c}$. Portlandite and calcite were observed at the interface between the matrix and the fibre, which correspond to dissolution and precipitation and of calcium-based phases (i.e. reprecipitation), that eventually carbonated.

A closer inspection of the damage and reprecipitation processes at the interface between the fibre and the matrix is presented in Fig. 8. The interface of an unexposed fibre, see Fig. 8a, generally did not show a distinctive microstructure compared to the bulk paste or the interface of an aggregate; nonetheless, local defects such a pores or mechanical damage were also found. There was limited mechanical damage to the matrix around the stem of the fibre (Fig. 8a), which presented minor re-precipitation of cryptocrystalline portlandite in some cases. In the case of the exposed specimens, most of the voids generated along the fibre surface during pull-out were generally lined with either cryptocrystalline portlandite (see Fig. 8b), and corrosion products (iron oxides) in fewer cases (Fig. 8c). Some locations showed carbonation of the matrix around the fibre at damaged areas, where the interface and surrounding voids were filled by a combination of corrosion products and calcite (Fig. 8d).

\section{Discussion}

The observations presented in the results section described the global and local damage observed at the steel fibre and in the matrix surrounding the fibre. The results are discussed below in order to clarify whether variations in the pull-out behaviour of partially-pulled fibres exposed to wet-dry cycles may be due to accumulation of corrosion products $[2,14,27]$ or healing processes in the matrix around the fibres $[9,17]$. Results from pull-out experiments on specimens re-tested after exposure to freshwater or saltwater cycles performed in [9] were used as reference, see Fig. 9. There were three main aspects that indicated an alteration of the pull-out behaviour of corresponding specimens: i) a partial restoration of the adhesive bond after exposure, ii) an increase of the maximum pull-out force at a slip of approximately $0.5 \mathrm{~mm}$ (i.e. an increase in the range of $50-100 \mathrm{~N}$ ), and iii) the unexpected rupture of some fibres at slip values much larger than the one corresponding to the maximum force.

\subsection{Pull-out behaviour and mechanical damage}

The observations presented in the results section show that most of the load transfer in the fibres investigated occurred at the hook. Most of the mechanical damage in the matrix were also observed at the hook region; corresponding to crushing of the matrix at one side of the hook, and separation at the

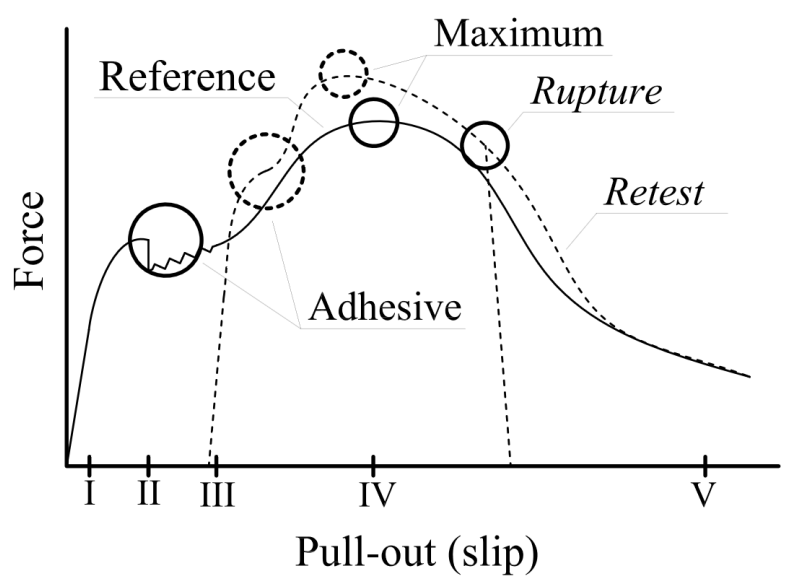

$$
\begin{array}{ll}
\text { Slip values (indicative) } & \\
\text { I }: 20-50 \mu \mathrm{m} & \text { IV }: 0.5-1 \mathrm{~mm} \\
\text { II }: 50-100 \mu \mathrm{m} & \mathrm{V}: 5-6 \mathrm{~mm} \\
\text { III }: 100-200 \mu \mathrm{m} &
\end{array}
$$

Fig. 9. Representation of changes in the pull-out forces transferred in partially pulled steel fibres exposed to wet-dry cycles, after [9]. 
opposite side. There was substantial abrasion of the steel at the straightened hook after the pull-out process; while the surface roughness at the stem did not vary regardless of presence of rust spots or compared to the original fibre (e.g. non-embedded).

These arguments support that most of the pull-out process of hooked-end steel fibres is actually governed by yielding of steel at the hook, fracture of the matrix around the hook and friction between the hook and the matrix, which is in agreement with former studies [12,28].

\subsection{Deterioration processes}

Accumulation of corrosion products occurred mainly at the intersection of the fibre with the crack extending approximately $1-2 \mathrm{~mm}$ into the matrix. Rust filled adjacent voids/damage and pores and was more abundant under chloride exposure. Small accumulation of corrosion products was observed in the hook region, which partly filled some of the voids/damage around the hook.

There were no signs of alteration of the bulk fibre roughness due to corrosion, for the exposures investigated in this study. Alteration of the matrix around the fibre and re-precipitation processes were found along the whole fibre but were more pronounced at the intersection of the fibre and the crack and at the hook. Sings of re-precipitation inside cracks, voids and separation damage around the fibre, comprising portlandite and calcite, indicate initial stages of autogenous healing of damage around the fibre, as also discussed in [29] at the composite scale.

Additionally, signs of carbonation of the cement paste surrounding the fibre were found, which may alter the mechanical properties of the adjacent matrix over time, e.g. stiffness, hardness and strength [30].

\subsection{Relating deterioration processes and pull-out behaviour}

Based on the observations discussed above, the pullout process of hooked-end fibres in concrete described in [9] and the deterioration processes discussed in [29,31] may be connected, as shown in Fig. 10. The pull-out path of an unexposed fibre may follow the steps shown in Fig. 10a-b, while, exposure of the fibre and matrix after partial pull-out (Fig. 10a) may lead to variations in the pull-out process, as shown in (Fig. 10c-d) and discussed hereafter.

The partial restoration of the adhesive bond reported after exposure may be explained by a combination of precipitation of portlandite and formation of calcite around the fractured fibre-matrix interface and formation (and localized expansion) of corrosion products at the intersection of the fibre with the matrix, see Fig. 10c. Subsequent strain and fracture of these under axial re-loading of the fibre may provide sufficient bond at small slip values, e.g. below $30 \mu \mathrm{m}$. In this aspect, accumulation of rust at the intersection with the crack could have an important role, considering that for example an increase in the pull-out force of up to $10 \mathrm{~N}$ distributed along approx. $2 \mathrm{~mm}$ of the fibre investigated would be equivalent to an average additional shear stress localized in this region of approx. $2 \mathrm{MPa}$. That is in agreement with values presented for corroded reinforcement bars (approx. 2 - $4 \mathrm{MPa}$ ) [32,33], also measured at small slip values during the de-bonding phase.

The increase of the mechanical bond strength, e.g. observed by an increase of the pull-out force by $50-$ $100 \mathrm{~N}$ at slip values up to approx. $0.5 \mathrm{~mm}$, is expected to be governed by the accumulation of solid phases (e.g. portlandite, calcite and iron oxides) at voids and cracks around the fibre (Fig. 10d). Filling up of voids a)

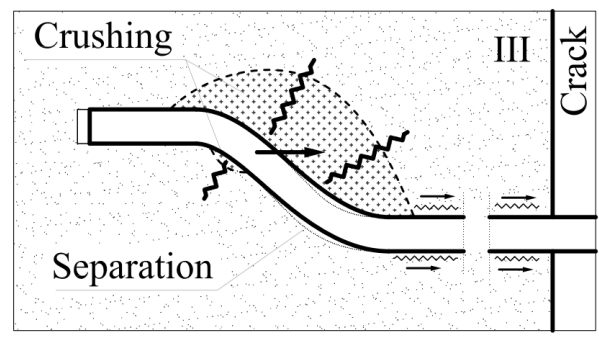

c)

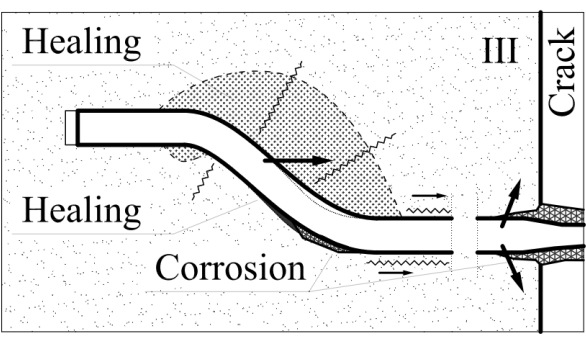

b)

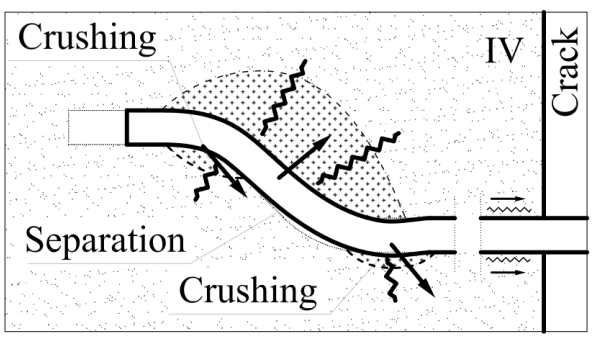

d)

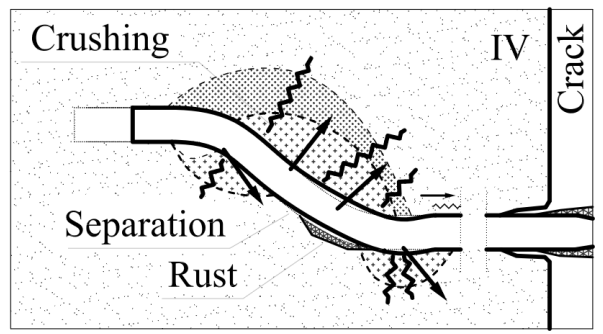

Fig. 10. Conceptual representation of the pull-out process of a fibre at various stages: a) initial damage after debonding, b) utilization of mechanical bond under normal conditions, c) reactivation of the adhesive bond after exposure, d) utilization of mechanical bond after exposure. 
and damage around the fibre alters the pull-out path of the fibre, leaving a narrower channel for the hook to bend afterwards. Carbonation of the cement matrix around the fibre and the precipitated portlandite may increase the hardness of the paste around the fibre, thus increasing friction. In this case, the hypothesis suggesting that the increase of the maximum pull-out force was due to additional friction caused by accumulation of rust at the outermost $2 \mathrm{~mm}$ of the fibre was discarded. Such an increase in the force would be equivalent to an additional frictional stress over that area in the range $10-20 \mathrm{MPa}$, that should lead instead to failure of the matrix. Yet, the contribution of accumulation of rust at voids and separation damage around the hook, despite minor, may have a contribution to the increase of pull-out forces transferred.

Rupture of the fibre at the hook in the descending branch of the pull out process, e.g. at $2.5-4 \mathrm{~mm}$ slip, could be explained as well by the mechanisms governing the increase of the mechanical bond strength. The alteration of the pull-out path of the fibre increases the frictional forces transferred through the hook, which leads to accumulation of additional yield strain at the hook bends and exceeds the local tensile limit of the steel at the deforming regions of the fibre. Corrosion damage at the hook could contribute to an early rupture of the fibres at the hook, but the extent of this contribution is not clear from the data available. Small corrosion spots, of approx. $1 \mathrm{~mm}^{2}$, were observed at the hook, but these did not entail a measurable reduction of the crosssection at the steel surface with the methods used.

\section{Conclusion}

This paper investigated the governing processes taking place during the exposure of partially pulledout steel fibres to wet-dry cycles of chlorides and $\mathrm{CO}_{2}$. The discussion described the processes that altered the pull-out behaviour of hooked-end steel fibres in companion specimens, which did not solely comprise corrosion damage of the fibre, and led to the following conclusions:

- Corrosion damage occurred mainly in the fibre region exposed directly to the crack and corrosion products precipitated in the matrix surrounding the fibre and adjacent to the crack. Limited corrosion damage was observed in the fibre region embedded in the matrix, which did not alter the surface roughness of the fibre.

- Mechanical damage observed in the matrix and at the fibre confirmed that the pull-out process is governed by yielding of the hook and fracture of the adjacent matrix. Most of the friction between the fibre and matrix was transferred through the hook.

- The partial restoration of the adhesive bond reported in companion specimens was attributed to a combination of autogenous healing around the fractured fibre-matrix interface and accumulation of corrosion products around the intersection of the fibre with the matrix.

- The increase of the mechanical bond strength reported in companion specimens was ascribed to the precipitation of solid phases, e.g. portlandite, calcite and to a lesser extent iron oxides, in voids and cracks of the matrix around the fibre hook. The accumulation of these phases reduced the free-space available for the fibre hook to yield, and led in some cases to premature rupture of the fibre at the hook bends.

These conclusions support recent hypotheses, which suggest that corrosion damage may not dominate the deterioration of the residual tensile strength of cracked SFRC exposed to wet-dry cycles, contrary to what was reported in former studies. However, further experimental and numerical investigations are needed in order to quantify the role of healing and deterioration processes at the fibre-matrix interface on the variations of the pull-out performance of hooked-end fibres in cracked concrete.

\section{Acknowledgements}

The first author would like to express his gratitude to: CowiFonden, InnovationsFonden, the German association of steel fibre producers (VDS), VejDirektoratet and Mapei-Denmark, for supporting this project.

\section{References}

[1] V. Marcos-Meson, A. Michel, A. Solgaard, G. Fischer, C. Edvardsen, T.L. Skovhus, Corrosion resistance of steel fibre reinforced concrete - A literature review, Cem. Concr. Res. 103 (2018) 1-20. doi:10.1016/j.cemconres.2017.05.016.

[2] J.-L. Granju, S.U. Balouch, Corrosion of steel fibre reinforced concrete from the cracks, Cem. Concr. $\begin{array}{llll}\text { Res. } & 35 & \text { (2005) }\end{array}$ doi:10.1016/j.cemconres.2004.06.032.

[3] E.S. Bernard, Age-dependent changes in post-crack performance of fibre reinforced shotcrete linings, Tunn. Undergr. Sp. Technol. 49 (2015) 241-248. doi:10.1016/j.tust.2015.05.006.

[4] E.S. Bernard, Effect of Exposure on Post-crack Performance of FRC for Tunnel Segments, in: I. Vrkljan, Z. Dekovic, M. Dobrilovic, J. Likar, P. Miscevic (Eds.), SEE TunnelPromoting Tunneling SEE Reg. - ITA WTC 2015, ITA-AITES, 
Dubrovnik, Croatia, 2015: p. 13.

[5] V. Marcos-Meson, G. Fischer, C. Edvardsen, A. Solgaard, A. Michel, Mechanical performance of steel fibre reinforced concrete exposed to chlorides and carbon dioxide: results after one year (Manuscript submitted for publication), Mag. Concr. Res. (2018).

[6] V. Marcos-Meson, G. Fischer, A. Solgaard, C. Edvardsen, A. Michel, Development of the mechanical performance of steel fibre reinforced concrete exposed to wet-dry cycles of chlorides and carbon dioxide: results after two years (Manuscript submitted for publication), Mag. Concr. Res. (2019).

[7] R.J. Gray, Experimental techniques for measuring fibre/matrix interfacial bond shear strength, Int. J. Adhes. Adhes. 3 (1983) 197-202. doi:10.1016/01437496(83)90094-5.

[8] C. DiFrancia, T.C. Ward, R.O. Claus, The singlefibre pull-out test. 1: Review and interpretation, Compos. Part A Appl. Sci. Manuf. 27 (1996) 597612. doi:10.1016/1359-835X(95)00069-E.

[9] V. Marcos-Meson, G. Fischer, C. Edvardsen, A. Solgaard, A. Michel, Pull-out behaviour of hookedend steel fibres in cracked concrete exposed to wetdry cycles of chlorides and carbon dioxide mechanical performance (Manuscript submitted for publication), Constr. Build. Mater. (2019).

[10] I. Markovich, J.G.M. Van Mier, J.C. Walraven, Single fiber pullout from hybrid fiber reinforced concrete, Heron. 46 (2001) 191-200.

[11] P.D. Nieuwoudt, A.J. Babafemi, W.P. Boshoff, The response of cracked steel fibre reinforced concrete under various sustained stress levels on both the macro and single fibre level, Constr. Build. Mater. 156 (2017) 828-843. doi:10.1016/j.conbuildmat.2017.09.022.

[12] A. Bentur, S. Mindess, S. Diamond, Pull-out processes in steel fibre reinforced cement, Int. J. Cem. Compos. Light. Concr. 7 (1985) 29-37. doi:10.1016/0262-5075(85)90024-7.

[13] T.H. Ahn, D.J. Kim, S.H. Kang, Crack Self-Healing Behavior of High Performance Fiber Reinforced Cement Composites Under Various Environmental Conditions, in: Kris Zacny, R.B. Malla, W. Binienda (Eds.), Earth Sp. 2012, ASCE, Pasadena, United States, 2012: pp. 635-640.

[14] C. Frazão, J. Barros, A. Camões, A.C. Alves, L. Rocha, Corrosion effects on pullout behavior of hooked steel fibers in self-compacting concrete, Cem. Concr. Res. (2015). doi:10.1016/j.cemconres.2015.09.005.

[15] N. Banthia, C. Foy, Marine Curing of Steel Fiber Composites, J. Mater. Civ. Eng. 1 (1989) 86-96. doi:10.1061/(ASCE)0899-1561(1989)1:2(86).

[16] E. Alizade, F.J. Alaee, S. Zabihi, Effect of Steel Fiber Corrosion on Mechanical properties of Steel Fiber Reinforced Concrete, Asian J. Civ. Eng. 17 (2016) 147-158.

[17] R.J. Gray, Autogenous healing of fibre/matrix interfacial bond in fibre-reinforced mortar, Cem. Concr. Res. 14 (1984) 315-317. doi:10.1016/00088846(84)90047-4.

[18] T. Nishiwaki, S. Kwon, D. Homma, M. Yamada, H. Mihashi, Self-healing capability of fiber-reinforced cementitious composites for recovery of watertightness and mechanical properties, Materials (Basel). $\quad 7 \quad$ (2014) 2141-2154. doi: $10.3390 / \mathrm{ma} 7032141$.

[19] D. Homma, H. Mihashi, T. Nishiwaki, Self-Healing Capability of Fibre Reinforced Cementitious Composites, J. Adv. Concr. Technol. 7 (2009) 217 228. doi:10.3151/jact.7.217.

[20] A.K. Kragh, M.E. Carlsen, Development of fibrematrix bond over time, Technical University of Denmark, 2017.

[21] European Commitee for Standardization (CEN), Methods of test for mortar for masonry. Determination of consistence of fresh mortar, European Union, 1999.

[22] European Commitee for Standardization (CEN), Masonry cement. Test methods, European Union, 2016.

[23] European Commitee for Standardization (CEN), Fibres for concrete - Part 1: Steel fibres - Definitions, specifications and conformity, EN 14889-1:2006, European Union, 2006.

[24] R.J. Detwiler, L.J. Powers, U.H. Jakobsen, W.U. Ahmed, K.L. Scrivener, K.O. Kjellsen, Preparing specimens for microscopy, Concr. Int. 23 (2001) 5158.

[25] U.H. Jakobsen, L. Laugesen, N. Thaulow, Determination of water to cement ratio in hardened concrete by optical fluorescence microscopy., Sp 191. Water-Ceme (2000) 27-41.

[26] U.H. Jakobsen, K. De Weerdt, M.R. Geiker, Elemental zonation in marine concrete, Cem. Concr. $\begin{array}{llll}\text { Res. } & 85 & \text { (2016) }\end{array}$ doi:10.1016/j.cemconres.2016.02.006.

[27] E.S. Bernard, Durability of cracked fibre reinforced shotcrete, in: E.S. Bernard (Ed.), Shotcrete More Eng. Dev. Proc. Second Int. Conf. Eng. Dev. Shotcrete, A.A. Balkema Publishers, Sydney, Australia, 2004: pp. 59-66.

[28] K. Georgiadi-Stefanidi, E. Mistakidis, D. Pantousa, M. Zygomalas, Numerical modelling of the pull-out of hooked steel fibres from high-strength cementitious matrix, supplemented by experimental results, Constr. Build. Mater. 24 (2010) 2489-2506. doi:10.1016/j.conbuildmat.2010.06.007.

[29] V. Marcos-Meson, M. Geiker, G. Fischer, A. Solgaard, U.H. Jakobsen, C. Edvardsen, T. Danner, T.L. Skovhus, A. Michel, Durability of cracked SFRC exposed to wet-dry cycles of chlorides and carbon dioxide - multiscale deterioration phenomena (Manuscript submitted for publication), Cem. Concr. Res. (2019).

[30] B. Šavija, M. Luković, Carbonation of cement paste: Understanding, challenges, and opportunities, 
Constr. Build. Mater. 117 (2016) 285-301. doi:10.1016/j.conbuildmat.2016.04.138.

[31] V. Marcos-meson, A. Michel, A. Solgaard, G. Fischer, C. Edvardsen, T.L. Skovhus, Corrosion Resistance of Steel Fibre Reinforced Concrete - a Literature Review, in: H. Beushausen (Ed.), Fib Symp. 2016. Performance-Based Approaches Concr. Struct., FIB, Cape Town, ZA, 2016: pp. 121-122.

[32] A.A. Almusallam, A.S. Al-Gahtani, A.R. Aziz, Rasheeduzzafar, Effect of reinforcement corrosion on bond strength, Constr. Build. Mater. 10 (1996) 123-129. doi:10.1016/0950-0618(95)00077-1.

[33] H. Yalciner, O. Eren, S. Sensoy, An experimental study on the bond strength between reinforcement bars and concrete as a function of concrete cover, strength and corrosion level, Cem. Concr. Res. 42 (2012)

643-655.

doi:10.1016/j.cemconres.2012.01.003. 